\title{
When Participatory Design Becomes Policy: Technology Comprehension in Danish Education
}

\author{
Rachel Charlotte Smith, Claus Bossen, Christian Dindler, Ole Sejer Iversen \\ Center for Computational Thinking and Design \\ Aarhus University, Denmark \\ \{rsmith, clausbossen, dindler, oiversen\}@cc.au.dk
}

\begin{abstract}
While several studies have addressed the challenge of sustaining PD initiatives over time and supporting largescale participatory processes, little is known about how $\mathrm{PD}$ and ideals fare on a national scale. We examine the process in which outcomes from a PD project were used and implemented as part of a mandatory course in Technology Comprehension in K9 education, commissioned by the Danish Ministry of Education. Our study is based on interviews with 12 people from the Danish educational sector, ranging from school teachers to the Minister of Education. Our findings demonstrate that while knowledge generated in a PD project can travel to the level of national policy, significant challenges emerge when outcomes from bottom-up PD is used in top-down policy. We conclude the paper by reflecting on how PD is equipped to create impact through policy.
\end{abstract}

\section{Author Keywords}

Policy, Education, Empowerment, Scale, Sustainability

\section{INTRODUCTION}

A persistent issue for participatory design (PD) is determining how the situated and specific nature of PD processes and their outcomes can be scaled, transformed and extended to achieve a wider and more enduring impact. In 2018, Frauenberger et al. [20] asked whether the inherently situated and 'idiosyncratic' nature of PD and its outcomes does in fact scale, and whether outcomes from PD are able to travel between contexts. A practical reason that this question remains relevant is the fact that there are few studies that report from instances where projects and outcomes are scaled and generalized. Several studies address large scale participation and sustaining initiatives within or around communities, but little is known about what happens, when PD outcomes reach the level of national policy.

This paper reports from a case in which the outcome of a PD project was used to launch a new mandatory course called

\section{PREPRINT}

Technology Comprehension (TC) in primary and lower secondary schools (K9) in Denmark. TC is presently taught in $43 \mathrm{~K} 9$ schools with the prospect of becoming part of all K9 schools in Denmark after the pilot test (2019-2021). The initiative was inspired and fundamentally influenced by, among other things, the idea of 'computational empowerment' which emerged from the Danish FabLab@School PD project. As we will demonstrate, the curricula for the course in TC is imbued with ideas and values that are traceable to the FabLab@School project and align with fundamental PD ideas of empowerment, democracy and a critical stance towards technology. As such, this case provides an opportunity for studying what happens when outcomes of a PD project are transformed to national policy and are adopted by people, who did not take part in PD activities. Our study consists of 12 qualitative interviews with persons involved in the TC initiative from various levels of the Danish educational system, ranging from primary school teachers to the Minister of Education. Our research interest is to understand the challenges and opportunities that emerge as the PD ideas reflected in the curriculum are disseminated at a national level, and adopted by recipients, who have not heard about PD. To do this, we set out to understand the extent to which PD aims and values are reflected in the educational stakeholders' understanding of TC and its relevance. Moreover, we explore the challenges of implementing and scaling TC and what PD might learn from this. Hence, our study contributes to ongoing PD discourses about the nature of PD results [9], how they are sustained $[32,36]$, scaled [31] and how PD may create a lasting impact on society $[7,34,38]$.

The paper is structured as follows. In the introductory parts of the paper we review the PD literature concerning scale and sustainability in PD and present TC, its central components, and how it incorporates PD elements. We then proceed to describe our method, before engaging with the results of our study and our analysis. In the concluding paragraphs, we discuss how our results relate to existing PD literature and the challenge that we believe this work poses for the PD community.

\section{RELATED WORK}

Our study of how PD outcomes travel and create impact weaves into long-standing discourses on how PD values such as democracy, empowerment and learning are pursued, and 
how PD's achievements are sustained, scaled and create impact for people and organizations.

PD's attention to fundamental values of democracy and empowerment, engaging stakeholders and communities to participate in the development of and decisions concerning their own future has been fundamental since its inception [37]. In the early Scandinavian projects this was evident in the approach to support local knowledge development and in an explicit political engagement [3]. While PD's level of political engagement is the subject of recurring critique $[2,6$, $28]$, there is ample evidence of the political agenda finding new forms in the PD literature, re-accentuating fundamental aims of empowerment, quality and democracy. These range from empowering rural communities [40] to politics of data care [1], the structures of power influencing PD in conflict areas [16], and to broader concepts such as 'commons' [39] and 'design things' [19]. While the commitment to PD values and aims is evident in this literature, there is a persistent challenge in making sure that the achievements made in a project or initiative will be sustained, and have enduring value for the people involved [33].

On a general level, it may be argued that sustainability of results and a commitment to creating lasting impacts is an inherent part of PD. In the early PD projects, this concern was addressed by not only developing novel technological systems, but also by developing local knowledge and making sure that experiences were shared between unions and workers [3]. Also, an important part of the output from these projects was reports capturing experiences with knowledge and educational material. The idea of PD as a learning process has since become a cornerstone through the concept of 'mutual learning' [37]. The PD literature also contains more specific reflections on the mechanisms and circumstances that promote sustainability and scalability of project achievements. Recent years have seen a renewed interest in the structures promoting enduring collaborations and political engagement. These include reports from Living Labs [4], practices of infrastructuring [27], reengagements with institutions [23] and a focus on the establishment of stable organizations for maintaining democratic control [29].

The importance of more or less formalized social networks of people has been a continuous theme in the PD literature regarding sustainability. As early as 1993, Clement and Van den Besselaar [12] noted the importance of participants becoming 'animators' in the projects, and Carroll et al. [10] reflect on the significance of teachers moving from informants to designers and coaches for their colleagues. Similar conclusions are drawn by Carroll and Rosson [11] and Merkel et al. [30], who stress the importance of social networks in terms of sustaining project achievements, and by Bossen et al. [8], who demonstrate how sustainability is achieved through indirect channels and across organizations. Dindler and Iversen [18] extend these insights suggesting that indeed 'relational expertise' should be considered a particular kind of PD expertise.
A central concern regarding sustainability is the scale of PD projects and how individual project achievements can be scaled to create change and impact in other areas [38]. It has been noted that PD is often carried out in small-scale, situated projects involving small-scale information systems (e.g. $[12,35])$. Calls have been made for the PD community to engage more directly in the procurement and development of large-scale systems and challenges [7, 34]. Moreover, the situated and particular nature of much PD work means that outcomes often develop an 'idiosyncratic nature' [20] making it difficult or impossible to generalise and apply elsewhere. Countering the inclination for local and smallscale projects, a body of work addresses the challenges arising from large scale PD projects (e.g. [14, 31, 35]). Other sources have discussed how results from one project may travel or be 'replicated' elsewhere [25]. A shared anchor point in the discourse on the scale of PD is the work by Gärtner and Wagner [21], which identifies three distinct 'arenas' of participatory work: designing work and systems, designing organisational frameworks, and designing the industrial relations context.

In sum, there is already a body of knowledge addressing how PD values are pursued and may be sustained through formal and informal networks, the establishment of institutions, infrastructuring and scalability. However, to the best of our knowledge there is little if no work in PD reporting on project achievements reaching the level of national policy. An exception is found in Norweigan technology agreements that grew out of early Scandinavian projects, and regulated the procurement and development of technology [3], but the process surrounding their development, deployment and effects are sparsely described. Also, there is a substantial literature on policy implementation in general but this is outside the scope of this paper.

Within the framing presented by Gärtner and Wagner [21], our research deals specifically with the last of the three arenas where 'the general legal and political framework is negotiated' [ibid, p197]. In particular, we deal with the challenges, opportunities and mechanisms at play when a project and its outcome is scaled and transformed from a relatively local context all the way to the national level. In our case, insights developed in a PD project were transformed into policy and - following Frauenberger et al.'s [20] concern around how PD travels - we find it relevant to shed light on this process.

\section{TECHNOLOGY COMPREHENSION IN DANISH K9 EDUCATION}

The PD outcomes that we set out to study in this paper is a course on TC developed for Danish K9 education. In this section we provide an introduction to the course and how it relates to PD.

In recent years, the educational sectors around the world have begun to address the challenge of digital transformation in educational programs [5]. While there are differences, there is a clear tendency to develop curricula based on 
STEM-inspired approaches to computational thinking, which often leads to a primary focus on skills related to programming, modelling and problem decomposition. Prominent examples include the K-12 Computer Science Framework [26] in the US, Computing At Schools in the UK [13], CoolThink in Hong Kong [22] and Digital Technologies introduced as a national curriculum in Australia [17]. In Denmark, the effort to develop K9 educational content around digital technology has reflected a somewhat different approach. The development of the educational program was commissioned by the Danish Ministry of Education, who requested that the ideas manifested in the concept of computational empowerment [24] should be reflected in the curricula alongside computational thinking. The concept of computational empowerment grew out of research in the Danish FabLab@School project (2013-2018), which was carried out in collaboration with four municipalities in the Eastern region of Jutland, Denmark. The cornerstone of the project was a participatory process involving pupils, teachers, lab leaders and local policy makers to explore the core challenges and opportunities of integrating digital technology in educational contexts. Some of the main outcomes of the project were new understandings of children's digital design literacy, a design-based model and approach for complex problem solving and digital technology, and a vast regional network and infrastructure of stakeholders collaboratively working with the same visions [38]. Computational empowerment emerged based on this research as a re-articulation of classic PD ideas of empowerment, democracy and emancipation in the context of education [24]. Computational empowerment is defined as a process in which children develop the skills, insights and capacities needed to engage critically and constructively with how digital technology affects their lives as individuals and groups [24]. As such, central PD ideas were explicitly infused in the TC curricula. This was evident in at least two respects. First, the researchers that coined the idea of computational empowerment, based on the Danish FabLab@School project, were invited to take part in the group assigned with the task of writing the curricula. Second, the primary investigator of the FabLab@School project acted as co-chairman of the group consisting of 25 experts within education and technology. Third, the curricula content reflects a concern for computational empowerment by emphasizing children's ability to critically reflect on technology, how it affects their lives and by focusing on their ability to frame complex problems and work iteratively with digital construction. Specifically, the course on TC is built around four main areas of knowledge and competence (figure 1):

Digital Empowerment: the critical and constructive exploration and analysis of how technology is imbued with values and intentions, and how it shapes our lives.

Digital Design and Design Processes: the ability to frame problems within a complex problem area and, through iterative processes, generate new ideas that can be transformed into form and content in interactive prototypes.

Computational Thinking: the ability to translate a complex problem into a possible digital solution, and the abstraction of phenomena and relationships in the world and the computer's ability to process this information.

Technological Knowledge and Skills: the ability to understand and use digital technology as a material for developing digital artifacts.

\begin{tabular}{|c|c|}
\hline  & $\begin{array}{l}\text { Digital empowerment } \\
\text { Critical, reflexive and constructive examination and understanding of possibilities and } \\
\text { consequences of digital artefacts. } \\
\text { Analysis of technology-intention and use | Evaluation | Redesign }\end{array}$ \\
\hline 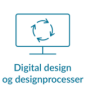 & $\begin{array}{l}\text { Digital design and design processes } \\
\text { Organisation and implementation of iterative and incremental design processes } \\
\text { considering the context of future use. } \\
\text { Problem framing | Ideation | Prototyping | Argumentation }\end{array}$ \\
\hline $\begin{array}{c}\text { Computatainel } \\
\text { tankezange }\end{array}$ & $\begin{array}{l}\text { Computational thinking } \\
\text { Analysis, modelling and structuring of data and data processes } \\
\text { for automatic execution by a computer. } \\
\text { Data | Algorithms | Structuring | Modelling }\end{array}$ \\
\hline 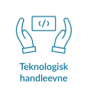 & $\begin{array}{l}\text { Technological knowledge and skills } \\
\text { "Mastery" of digital technologies (computer systems and networks), associated } \\
\text { languages and programming. } \\
\text { Programming | Computer systems | Networks | Security }\end{array}$ \\
\hline
\end{tabular}

Figure 1. The four competence areas in the Technology Comprehension curriculum.

The lineage from computational empowerment and PD is particularly evident in the areas of Digital Empowerment and Digital Design and Design Processes. It is however also evident when looking at the goal description of the curriculum where the need for skills to proactively engage in the digitization of society are accentuated:

"In Technology Comprehension students gain skills to understand the capabilities of digital technologies and the implications of digital artifacts in order to strengthen students' capacity for understanding, creating and acting meaningfully in a digitized society where digital technologies and digital artifacts are catalysts for change" [15].

Moreover, TC is articulated as a support for intellectual freedom and a democratic citizenship among students:

"Intellectual freedom and democratic citizenship are widely cultivated in digital environments, which is why a technologically founded understanding of technology is a prerequisite for being able to contribute constructively and actively in the development of relationships, communities and societies" [15].

These concerns for students' active engagement in technology development, democratic citizenship and intellectual freedom permeate the TC curriculum and can be traced throughout the four competence areas. Most evidently, the Design and Design Process competence area is participatory in nature, emphasizing user studies as a prerequisite for new design [15]. Moreover, Digital Empowerment provides students with skills for analyzing 
and reflecting on how digital technologies are imbued with values and how they affect our everyday lives, our communities and society at large [15].

\section{METHODS}

To study how PD ideas were reflected in the TC initiative, we conducted semi-structured interviews with 12 individuals with different kinds of involvement with the development and implementation of TC. When selecting interviewees, we aimed to recruit participants from a diversity of roles within education, from government level to $\mathrm{K} 9$ teachers, and geographical area, including Jutland and Zealand. None of the interviewees had been directly involved in the development of the curricula, with the exception of the Minister of Education and Head of Education and IT at government level who commissioned the TC initiative. The rest of the interviewees were champions in local and/or regional TC curriculum development at their particular level of authority. Hence, each interviewee had knowledge of the subject matter relevant to their role, were familiar with curriculum of $\mathrm{TC}$, and are currently involved in the implementation of TC.

\begin{tabular}{|l|l|}
\hline Work position/title & Duration \\
\hline 1. Minister of Education (Government) & $33 \mathrm{~min}$ \\
\hline 2. Head of Education \& IT (Government) & $42 \mathrm{~min}$ \\
\hline 3. Head of Dept., Teachers' College, Jutland & $35 \mathrm{~min}$ \\
\hline 4. Head of Dept., Teachers' College, Zealand & $50 \mathrm{~min}$ \\
\hline 5. Lecturer, Teachers' College, Jutland & $33 \mathrm{~min}$ \\
\hline 6. Lecturer, Teachers' College, Zealand & $43 \mathrm{~min}$ \\
\hline 7. Teaching Consultant (Municipality), Zealand & $43 \mathrm{~min}$ \\
\hline 8. Head of Education \& IT (Municipality) Jutland & $44 \mathrm{~min}$ \\
\hline 9. School Principal, Jutland & $34 \mathrm{~min}$ \\
\hline 10. School Principal, Zealand & $39 \mathrm{~min}$ \\
\hline 11. Teacher (K9), Jutland & $37 \mathrm{~min}$ \\
\hline 12. Teacher (K9), Zealand & $39 \mathrm{~min}$ \\
\hline
\end{tabular}

Table 1. Interviewees and interview duration

Interviewees, aside from the Minister and the Head of Education and IT, included two heads of education from two municipalities, as municipalities are responsible for primary and secondary schools; two heads of departments at two teachers' colleges, as the teachers' colleges are responsible for developing the courses through which future K9 teachers gain competences in teaching TC; two lecturers at teachers' colleges teaching the new subject; and two K9 school principals and two $\mathrm{K} 9$ teachers involved in teaching $\mathrm{TC}$ as part of its pilot study. In total, the 12 interviews amounted to 472 minutes with an average of 39 min (shortest $33 \mathrm{~min}$; longest $50 \mathrm{~min}$, Table 1). All interviews were conducted by one of the authors; a PD researcher not previously involved in the educational research projects. The researcher visited the participants in Jutland and Zealand in June 2019 to conduct interviews in their own working environments. Informed consent about the research results and the partial anonymity of the interviewees was given by all participants - partial in the sense that the Minister of Education and the Head of Education \& IT are public known figures. The interviews were transcribed and analysed for cross-cutting themes by the four co-authors through a series of collaborative iterations.

\section{ANALYSIS AND FINDINGS}

To understand how our interviewees perceived TC and the subsequent PD ideas underpinning the TC curriculum, we asked them to share their understanding of the motivation for introducing TC, the content of the course and how it could be operationalised in practices and activities. In this section, we present results from our analysis of the interviews. The results are structured around three main themes that emerged from the thematic analysis: democracy and citizenship; technology and learning; and sustainability and scale. The themes of democracy and citizenship, and technology and learning were two recurrent issues that emerged from questions regarding the content and motivation for TC. The third theme regarding sustainability and scale emerged from questions about putting TC into practice.

\section{Democracy and Citizenship}

One way to gain insight into how TC was perceived and understood by the various interviewees was to raise the question of why they considered TC to be an important subject for primary and secondary education. This question pointed mainly to the visions for introducing $\mathrm{TC}$ in education, and was closely related to a question about the expected gains of TC. Below the answers provided to the two questions are structured around three topics: The ubiquity and understanding of technology; democracy and citizenship; and labour markets and industrial competitiveness.

\section{Ubiquity of technology}

A common starting point for most interviewees to the question of 'why TC?' was to point at the presence of technology everywhere in contemporary society, as these two citations illustrate:

“... technology is here to stay and we cannot ignore how much it's part of our everyday life. It's part of reality and to disregard this, or exclude it from primary schooling would be bizarre...we need to incorporate it. Critically and constructively" (12. Teacher, Zealand).

"...children today grow up in a society where you cannot not relate to the digital. It is ubiquitous and therefore we have to enable them to navigate in a society, where digital 
technologies are so dominant" (10. School Principal, Zealand).

This understanding that IT is now ubiquitous formed the primary motivation for primary and secondary schools to want to build the digital competences of children so they would become competent and active participants in a democratic society, with the necessary skills to participate in further education and the labour market.

When asked about the expected gains of TC, the majority of respondents described an ability to understand the influence and consequence of digital technology in relation to children's everyday lives and broader society. For example, a teacher expects TC to provide children with a better understanding of their life worlds, a consultant expects that they will gain a better understanding of their online presence (and social media use), and a manager at a teachers' college envisions a future in which TC becomes a requirement for understanding our society at large. He states:

"Our society is so swamped in digital technology that it is simply necessary for our children to have a thorough understanding of digitalization, and to possess technological abilities and digital empowerment as part of their education. So, we will have to provide them the necessary resources to act in society and in the global world we live in. This is essential" (4. Head of Dept, Teachers' College, Jutland)

\section{Technology, Citizenship and Democracy}

The question of democracy was raised in relation to TC at all levels of the educational system by our interviewees as both reasons for and potential gains. Thus, for example, the Minister of Education stated:

"Technology is such a large part of everything that it also relates to citizenship. You need to understand technology in order to own your role as a citizen, as a critical citizen, as a democratic citizen" (1. Minister of Education)

A head of department at a teachers' college stated:

"You don't achieve democracy without profound competence in technology comprehension" (...) "This course [TC] can ensure a kind of digital 'Bildung' that makes us better democratic citizens, ... to me it's not only a technological project. It is a societal project and a democratic project” (4. Head of Dept., Teachers' College, Zealand).

Moving beyond technology as a basic premise of society, there were different perspectives raised within the theme of democracy. TC was thought to contribute to one's intellectual freedom by building children's digital competences. Through learning, children were better equipped to be critical about the social media posts they encounter, and act appropriately within these contexts. The

\footnotetext{
1 The Danish word is 'dannelse', similar to the German word 'bildung' designating personal growth and maturation of mind and heart. A translation into English is difficult.
}

'capacity to act' was a recurrent theme in the interviews, where interviewees pointed to personal and societal gains from learning of this kind. One head of a teachers' college pointed at the ability to decode:

"To have a working democracy, we need to be able to decode not only the intentionality of technology, but also the intentionality of communication. That is, we need to be critical in a way that we're not quite ready for yet, today" (4. Head of Dept., Teachers' College, Zealand)

In some instances, the relation to democracy took a darker turn, as the perceived dangers of technology made TC not only relevant, but also pertinent for a democracy. A lecturer argued the following:

“... we see daily how technology has a role in undermining democracy ... fake news, deep fakes - you know where another voice is imposed on video. Technology threatens democracy sometimes" (6. Lecturer, Teachers' College, Zealand)

Likewise, the head of a teachers' college speaking of the recent governments in Italy and the US stated that:

"This [TC] is a societal project and a democratic project. If the development in Southern Europe and on the other side of the Atlantic continues, then democracy is in danger of dissolving through fake news and a new form of political communication" (4. Head of Dept., Teachers' College, Zealand")

When exploring the expected gains, the vast majority of interviewees point to the importance of building digital competences to promote democracy, citizenship and to reverse the (digital) divide and other societal inequalities. Some interviewees point to the fact that dialogue on societal issues and politics most often occurs on digital platforms and social media, therefore children must possess the ability to act with proficiency and critically reflect on the digital media to engage in the democratic dialogue.

Others, such as the Minister of Education, take this perspective a step further by arguing that digital technology is the new infrastructure of modern society. Where children were previously taught the names of European rivers to understand our logistic infrastructure, future generations must learn about digital technologies as they represent the primary infrastructures of democracy, trade, communication and power. As argued by the Minister:

“... One must understand technology as a premise, one must understand it as infrastructure, one must understand it as a communication tool, one must understand it as a generator of power, or more generally as a place where democracy or the opposite unfolds." (1. Minister of Education). 
Labour market and industrial competitiveness

Closely linked to the question of democracy and citizenship, was the question of providing children with competences for the future labour market. This was raised in relation to the emergence and development of $\mathrm{TC}$ as a course for $\mathrm{K} 9$ education, since different sectors and interest groups had lobbied for coding to become part of public schools. The focus on labour market competences appeared at all levels of authority with our interviewees as the following three citation exemplify:

"[Learning TC is] an opportunity to be able to make a living as an individual" (4. Head of Dept., Teachers' College, Zealand);

"...there are less and less jobs where you cannot know about this [TC]” (2. Head of Education \& IT, Government)

“...competing internationally within knowledge, which is what's emphasized in Denmark, we need to have people who know about technology and want to learn more about technology in further education" (12. Teacher, Zealand)

Often, the attention to democracy and 'bildung' - forming mature and competent humans - was raised in the same sentence as the need to provide competences for the labour market. Most interviewees acknowledged the need to attend to both aims in a balanced way, but not always as demonstrated in this quote by one primary teacher:

"... you want to teach to a labour market even though you don't quite know what it looks like in 10 or 20 years. So it might be on terms stated by the labour market. However, I think it [TC] is more important in relation to the formation of whole persons, and how we as individuals and collectives handle technology and its influence on us as humans" (12. Teacher, Zealand)

In summary, all interviewees agree on the fundamental reasons for $\mathrm{TC}$ and its expected gains from personal to societal level. None of the interviewees raised arguments against the relevance of $\mathrm{TC}$, which is not surprising considering their interest in promoting teaching about technology in primary schools, and their varying degree of involvement in its development and implementation. The relevance of TC for democracy was viewed as a straightforward component of building 'competent citizens' in a democratic and digitalised society. Hence, across levels of authority the interviewees point to similar visions and gains of TC. They point to external factors of the changing labour market, political systems, social media, and to personal and societal gains of teaching future generations to navigate as citizens in a digitalised society.

\section{Technology and Learning}

Another central theme from our findings concerned TC's subject matter. The interviewees were asked about their own understandings of TC, and how they envisioned it to be integrated with existing subjects and teaching practices. These discussions were then explored with reference to the four areas of knowledge and competence within the curriculum (see Fig. 1 above). Three overarching topics emerged from the material regarding the cohesion, composition and implementation of $\mathrm{TC}$ in $\mathrm{K} 9$ education. It is important to note that TC is currently tested in two versions in Danish K9. Twenty-three schools have introduced an independent and mandatory 2-h weekly course, whereas the other 23 schools have integrated $\mathrm{TC}$ as a versatile competence across seven existing mandatory courses such as Math, Science, English and Music.

\section{Cohesion of knowledge and competence areas}

The topic of cohesion between competence areas is addressed by most interviewees but in divergent ways. Regarding the cohesion of the four areas of knowledge and competence, the Head of Education \& IT (Government) refers specifically to the curriculum and points out that the four areas cannot be separated. The Minister of Education argues that Digital Empowerment is the most important area and should be regarded as "the bar" since it most clearly articulates the importance of democracy, citizenship and the values that underpin Scandinavian societies. Among the teachers and consultants, most report that they believe that the four areas are tightly connected and cannot be separated. A Lecturer at the Teachers' College (3. Jutland) explains:

"...it was never the idea that... so ok, today we are doing digital empowerment. So now I will give you some empowerment. 'Shh.., quiet in the back row!' That's not how we teach it [Digital Empowerment]"

Although there is agreement among the teachers that the areas are connected, they differ in terms of the importance ascribed to them. Some of the teachers favor Digital Empowerment and argue, similar to the Minister, that this area brings everything together, while others believe that Technological Ability is in fact more important.

Composition - Humanities and STEM

Regarding the way in which TC is composed, the interviewees address several aspects. Both K9 teachers, school principals and lecturers at Teachers' College argue that Digital Empowerment is well-aligned with the values inherent in the Danish school system and, as such, it will not be difficult to implement. Also, the respondents argue that its focus on critical thinking and analysis is already practiced in other guises in the arts in K9. On the other hand, both teachers and principals note that Technological Ability and Computational Thinking will prove more difficult in practice. A lecturer explains:

"So, if one were to point to our weakness it will clearly be in the technological abilities where there is a big gap compared to other countries" He broadens the concern by explaining: "...So it's the hands-on side of things. That is what's missing. It still is. The Danes are not good enough with their hands 
and not good enough at programming." (5. Lecturer, Teachers' College, Jutland).

Although there is consensus among the teachers and the school principals that the areas of Digital Empowerment and Digital Design \& Design Processes are relevant, they express concern that they do not have sufficient knowledge and skill to conduct teaching and that the curriculum is difficult to grasp and overly academic.

Another lecturer suggests that Computational Thinking and Ability might prove easier for the STEM teachers to work with. The issues of the relationship between STEM and the more critical and design-oriented subjects, is further addressed by the senior government official and the Lecturer (5. Teachers' College, Zealand), who explains:

"So you can see there has been a power struggle between those who would like to pull it [the course] in the direction of computational thinking and (...) and those who want to draw it in the direction of design. (...) So that is the span between technological ability and judgment."

The government Head of Education \& IT explains in detail the importance of appointing two academic researchers to head the working group for TC's curricula - one with a computer science background, and the other with a critical design-oriented background. He specifically mentions that the Ministry of Education chose the second researcher, because of the results of the FabLab@School.dk project and its success in developing new learning practices around technology and education.

\section{Implementation as independent or integrated subject}

Interviews revealed two disparate positions on how TC should be incorporated into current school processes, with some arguing for TC to be a standalone subject, and others argue for its integration across existing subjects. Interviewees generally recognize that $\mathrm{TC}$ is a new interdisciplinary subject integrating themes from humanities and computer science. Developing this subject has required that new subject matter and a coherent curricula be cultivated specifically for TC. Consequently, to establish a shared understanding among teachers nationwide, an independent TC course is considered to be the most efficient way of implementing a new subject.

"...The fastest and most effective way to get the new subject matter under your skin as a teacher is to implement it as an independent subject. Technology Comprehension would be visible on the schedule and this is what we [teachers and students] need to work on now." (11. Teacher, Jutland).

Treating TC as an independent course would deal with the challenge of distributed responsibility for the course among teachers. As expressed by the Minister:

"It is important that Technology Comprehension is not just implemented as a remote part of the existing subjects. We have experiences indicating that it would not lead to any useful outcomes. If the responsibility for a subject matter is distributed to everybody [teachers], no one will take full responsibility for this subject matter." (1. Minister of Education).

The need for a new beginning from previous technical courses in computing is articulated in some of the interviews. A principal argues:

"it is important to make a new beginning of this particular subject, and say, we have to try for a transitional period to work with Technology Comprehension separately as a subject, so that we can work up the competence and develop a subject that has its own professional language, before we can integrate it into other disciplines" (10. School Principal, Zealand).

At the same time, the interviewees generally recognize that TC is an interdisciplinary subject likely to affect all existing subjects. As pinpointed by a consultant: "I cannot imagine a single subject of those we have in primary school that does not radically change with digital technology" (7. Teaching Consultant, Zealand).

Others point to the fact that TC would have a wider appeal among a more diverse group of students, including female students who are reluctant towards TC, if introduced as part of the existing subjects. This would attract a broader range of humanistic-oriented teachers and improve their sense of ownership of the subject matter. Many interviewees reflect on the political process that will emerge from this experiment.

"When you introduce a new subject in schools something else will need to be removed. Or you will have to expand the school day or combine the new with the already existing. That will be a major political discussion." (2. Head of Education \& IT, Government).

In sum, it is clear from our findings that interviewees find the coherence of TC's subject matter important, and that each of the four subject areas contribute positively towards the visions stated above for TC in education. Many point to the importance of Digital Empowerment, which aligns well with the arts, and the fundamental values of the Danish educational system. Their concern is that the hands-on and technical elements will fail due to a lack of teacher competency. Reversely, it is argued that technical and practical subject areas might prove easier for the STEM teachers to work with. Teachers represent different interests and competences, from humanities and STEM, and the direction of TC in practice will depend on who is involved in its implementation.

Hence, there is a general uncertainty of what kind of educational practice that is currently being developed. There is a fear of 'a war of subjects' in which the visions for TC's subject matter become fragmented in practice. TC in its present form of written legislation, or pre-packaged 
generalised knowledge, needs to be implemented in practice, and built from the ground.

\section{Sustainable Scale}

The third overall theme that emerged from our analysis, concerned the challenges of scaling and sustaining TC. These themes emerged as respondents were asked to reflect on the challenges of implementing $\mathrm{TC}$ in the Danish educational system. Based on the analysis of challenges of TC we identified three overall themes pointing toward moving from small to large scale, the development of subject knowledge and teaching practices, and sustainability and the long-term. Some of the challenges connect directly to themes discussed above, e.g. TC's subject matter and the visions of TC. We will return to some of these connections in the discussion.

\section{Moving from small to large scale}

Unsurprisingly, many respondents point to the challenges of implementing TC as a new mandatory subject. Across all respondents there was a concern for time, resources and capacity building towards scaling up, and the uncertainty of political decision-making and support.

A large emphasis was placed on the teacher's lack of skills and knowledge. Interviewees both highlight the day-to-day working conditions in the educational system, which due to recent political reforms and cut-backs leave teachers with very little time for new initiatives. Moreover, at a structural level, respondents point to the teachers' lack of competences and training for teaching TC and the vast task of upgrading the entire force of teachers.

While capacity building (e.g. economic, organisational and human resources) and logistics of scaling up were highlighted as central challenges, surprisingly, digital technologies and learning environments for teaching TC were not mentioned. At a political level, stakeholders were concerned with capacity building and decision making processes in the political systems. They point to the lack of clear decisions concerning the pipeline or progression of TC through the educational system, from primary school to university level. Moreover, the logistic and structural challenges of implementing TC in 1100 Danish schools were of central concern. The government official stated:

"...that is part of the problem: How do we develop the necessary skills for educators on all levels fast enough? If we do what's normal and use the traditional channels, it would take far too many years. So, we need to do something else, probably also involving industry and funds to provide extra economic resources. We will need all forces to be involved, in order to get this up and running" (2. Head of Education \& IT, Government).

\section{Subject knowledge and new teaching practices}

As mentioned above one of the major gains of TC is its potential of bringing new approaches and teaching practices to K9 education. Problem-based learning, design processes and hands-on experiments however, are forms of explorative learning that need to be introduced into a contemporary educational culture that is increasingly defined by learning targets and national tests.

All interviewees point to the core challenge of developing TC's subject knowledge in practice. This work needs to be done from the ground up, since it is a completely new subject matter with no foundation in existing subjects. This demands developing the necessary didactics and pedagogy for introducing $\mathrm{TC}$ to the students. In particular, the teachers address the challenge of implementing new teaching practices in the classroom by pointing to three prototyped lesson plans provided from national level as a first take on how to teach TC:

"...the subject titles are fine, but the way of working is difficult for the students, where you need to be very experimental, do field studies, develop experiences and return to the process by moving back and forth all the time to optimise things and create the best result. This way of working in school is completely new (...) and the students have to get used to it" (11. Teacher, Jutland).

He continues by arguing that the process-orientation of TC demands new competencies from teachers that are difficult to acquire in an educational system driven by tests and measurable results, whereas in $\mathrm{TC}$ : “...here the process becomes a large part of the focus, when you go out and experiment to create new knowledge, and the teacher doesn't necessarily have the answer to where, but you have be cocreator of it. This is a large cultural change we need to make" (11. Teacher, Jutland).

Another teacher highlights the challenge of balancing TC between humanistic and STEM oriented subject knowledge. He argues that TC might appeal more readily to STEM subjects, where e.g. computational thinking is easily integrated into math and natural sciences. And the challenge is for the humanistic perspectives (and teachers) to claim connections between language, reflective thinking, learning processes, etc. to aspects of design thinking, wicked problems, real-life challenges, and so forth in order to build the students' computational empowerment based on the development of a solid pedagogy and didactic (12. Teacher, Zealand).

Related to TC's four competence areas, a large concern is developing teaching practices to support TC's creative and hands-on element. TC integrates both hands-on 'coding' and reflective 'decoding' as core competencies, and the constructive and processual elements are in most danger of 'falling outside' current educational practices.

"You can't work seriously with design processes without anyone being able to design anything. (...) That challenges the traditional learning environment where students are banked in lines of desks, while you (the teacher) broadcasts to them. It doesn't work" (12. Teacher, Zealand). 
Implementation and long-term commitment

The biggest challenges for integrating TC into the Danish school system over the next five to ten years, is clearly seen to be the ongoing support at the political level as well as finding ways to develop the teachers' skills. The political urge of implementing TC into the national curriculum means that teachers' and educational systems are under pressure to act fast and according to top-down demands, but without the necessary support, skills and resources.

"It really demands political tail wind. And sometimes it feels like politics happen based on a few headlines, and based on values rather than knowledge about what really makes a difference. That is the biggest challenge" (6. Lecturer, Teachers' College, Zealand).

In the same vein, the government's Head of Education an IT adds that sometimes one political project is substituted by the next, by a kind of "projectitis", that never really leads to long-term sustainable results due to lack of ongoing support. Several respondents point to the challenges for educators of turning TC's highly abstract and complex subject matter into practice in a meaningful and respectful way. Hence, the Minister suggests implementing TC through a progressive process, to support the local environments:

"Perhaps we need to implement it over the next 2-3 years, so we can add elements in different tempi. So, some schools need a more hand-held implementation than others. I think it's crucial to really think through this implementation so that the teachers don't feel that they are run over" (1. Minister of Education).

The other long-term challenge is educating the work-force both existing teachers and those in teachers' training - over the coming 5-10 years, to have the mindset, competencies and skills to teach TC across the educational system based on a coherent understanding and set of teaching practices. The biggest challenge for TC to be a success and not merely an abstract vision is, as argued by a manager:

"...to make the teacher in charge of the subject dedicated and skillful at it. That's crucial, and then to be engaged as a role model for the students who need to absorb the subject, the knowledge and understanding that the subject contains" (3. Head of Dept. Teachers' College, Jutland).

In sum, whereas interviewees on the level of democracy and citizenship clearly agree on the fundamental reasons for TC, its visions and expected gains, it is clear from the stakeholders' statements that challenges arise when it comes to the practical implementation and sustainable scaling of TC. In general, interviewees point to the lack of direction, content and organisation in the implementation of TC as a subject, including decisions over its educational pipeline and implementation from primary to higher level education.

\section{DISCUSSION}

Reflecting on how PD can extend its reach, Frauenberger et al. 2018 [20] asked whether PD does in fact scale and whether PD is able to travel between contexts. Our study suggests that PD values and ideas do in fact travel - perhaps surprisingly well. We can observe that across all levels of authority, the interviewees' overall understanding of the relevance and expected outcomes of TC aligns with PD objectives, even though interviewees are not familiar with PD and did not take part in the PD process leading up to the development of TC. Their point of reference for talking about TC is the curricula and any knowledge they may have gained from their prior work. Nonetheless, they generally provide clear and coherent explanations for why $\mathrm{TC}$ is necessary and how it is related to the educational goals of Danish primary schools, towards both personal and societal levels. They see TC as relevant for students' development of a critical engagement with technology where they can decode background intentions embedded in technology as well as code technology. Also, they argue that TC should both enable students to understand and assess the possibilities of technology as well as equip them with technological skills and knowledge. Almost all interviewees related such skillset to democratic concerns of citizenship and empowerment. Furthermore, the ways of working with the competences involved in Digital Design \& Design Processes are embraced, as they offer different teaching approaches to the traditional models of target-based learning, since these ways of working emphasize engagement and decision-making by the students in and about designing artefact. As such, there appears to be solid support for arguing that the PD ideas that were present in computational empowerment and later found their way to the TC curriculum have in fact successfully travelled and are now argued all the way from primary school teachers to the Minister of Education. A contributing factor to the positive reception of TC is probably that PD's aims align well with K9s' aims according to public law, which amongst other things states that "pupils should gain confidence in their own abilities and be able to form an opinion and act" and teaching should be carried by "freedom of spirit, equality and democracy".

However, it is also evident that the interviewees report significant challenges in relation to the TC course. There are challenges associated with aligning the new subject to fit into existing curricula - if a new course is introduced something else has to give way. Also, challenges are reported in terms of teacher training as very few teachers have any experience and the teachers' colleges lack the expertise necessary for training teachers. Finally, there is a lack of teaching material, whilst the teaching material available is difficult for the teachers to appropriate to their own teaching practices.

Despite the diversity of challenges mentioned, they all relate to the practice, activities and organizational setup that surrounds TC. Returning to the PD literature, it may be argued that the interviewees in fact point specifically to a lack of the kinds of social networks, infrastructures and situated knowledge which is developed and nourished in PD processes and form the grounds of sustainable practices (e.g. 
[10, 27, 30]), and that made the FabLab@School.dk initiative successful in particular regional contexts [38]. So, while we can observe that the motivations, values and ideals of PD have apparently travelled successfully and resonate on a conceptual level across all tiers of authority, this does not appear to be the case when it comes to practice. Frauenberger et al. [20] addressed this concern specifically, arguing that "the extreme idiographic nature of $P D$ work leads to the very real risk that the benefits of any knowledge constructed are eaten up by its contextual dependencies." In our case, the practices, activities, and organisational arrangements that were developed during the FabLab@School project and which was the context of the idea of computational empowerment, did not travel to national policy and is currently not scaled to the 46 schools where the TC course is running.

So, what does PD offer in terms of addressing this issue? As covered in the section on related work, the PD literature has several reports on how PD is sustained and how project achievements are scaled. Yet these often assume that PD is a bottom-up process, where scaling proceeds gradually from a local project to other arenas and sustainability rest upon infrastructuring [27], long-term engagement [10] and the gradual development of knowledge, practice and relational work [18]. In the case of TC, these approaches were, however, not viable because of the nature of the process. The TC initiative was commissioned by the Ministry of Education and was inherently framed as a top-down approach, based on the development of a curriculum to which teachers have to develop teaching practices.

Due to the Governments' focus on a fast implementation of the TC initiative, the process has lacked focus on bottom-up knowledge building and practice development. Moreover, opposite the FabLab@School project which built structures, networks and knowledge practices for technology education bottom-up, the TC initiative has been created around visions and knowledge transfer built into a curriculum. In this way, the move from bottom-up to top-down suspends the ways that PD would usually ensure sustainability and that ideas are anchored in the practice of participants. It may of course be argued, the researchers should have objected to the top-down model and urged the Ministry of Education to adopt a bottom-up strategy for developing and implementing TC in Danish K9 education. This would, however, hardly be realistic since scaling from a single project to the entire Danish school system would simply take too long. As the Minister of Education and the government Head of Education and IT stress, there was significant political pressure for Denmark to develop an educational initiative relating to digital technology, and in a political reality of shifting agendas this cannot wait for a long-term PD process to scale. The realistic alternative to developing a top-down curricula featuring PD ideas would be for the Danish Ministry of Education to adopt one of the STEM-inspired approaches already developed and running in educational programs across the world (e.g. CoolThink, CSforAll). So, the choice facing the researchers involved in developing the TC curriculum, was to either accept a top-down process or withdraw from the process, hereby letting go of the idea of computational empowerment to a primary focus on STEM inspired computational thinking. As is evident from this case, the researchers choose to engage in the governments' initiative to further ideas of empowerment, democracy and a critical approach to technology as a counterweight to computational thinking - at the expense of a PD process.

This study of the Danish TC project reveals an important research topic for future PD research. If PD is serious about achieving wider political impact, we argue that PD needs knowledge and instruments for engaging in these kinds of processes. In these processes it is likely that some of the existing PD approaches for ensuring scale and sustainability will be insufficient, because they assume long-term, bottomup processes. The question for PD research is how to engage in top-down policy-making without losing the grounding concerns for democracy, empowerment and quality. Also, it is necessary to consider not only how the knowledge developed in PD can travel, but how the practices and activities to which it is tied can travel or scale. Traces of how to address this can be found in the PD literature. Kyng [29] demonstrates the importance of establishing organizations in the interest of maintaining democratic control which could provide one way to engage in a large-scale reality where bottom-up PD does not work. Also, continuous advocacy for resources and time to connect bottom-up processes to established institutions in order to achieve impacts may be a necessary prerequisite for tying in PD agendas to large scale societal implementation.

\section{CONCLUSION}

Our study shows the opportunities and challenges that emerge as a PD outcome travels between a bottom-up PD process and top-down policy-making. As our analysis demonstrates, core values of democracy and empowerment from the PD process have traveled and are evident in the curricula and in the interviewees understanding of TC However, the top-down process of policy-making suffer from a lack of practice-related knowledge (the lack of TC knowledge among teachers, the missing infrastructure for capacity building, and the unclear process to implement TC as a subject) which was not transferred from the PD process. Our study calls for PD research on how to translate PD outcomes from situated projects to national policy-making in order for PD to strengthen and widen its political impact.

\section{ACKNOWLEDGMENTS}

This work has been funded by VILLUM FONDEN grant no 28831.

\section{REFERENCES}

[1] Baker, K.S. and Karasti, H. 2018. Data care and its politics. Proceedings of the 15th Participatory Design Conference on Full Papers - PDC '18.

[2] Beck, E.E. 2002. P for Political. Scandinavian Journal 
of Information Systems. 14, (2002).

[3] Bjerknes, G. et al. 1987. Computers and democracy: A Scandinavian challenge. Gower Pub Co.

[4] Björgvinsson, E. et al. 2010. Participatory design and democratizing innovation. Proceedings of the 11th Biennial participatory design conference (2010), 4150.

[5] Bocconi, S. et al. 2016. Developing Computational Thinking in Compulsory Education - Implications for policy and practice. Technical Report \#JRC104188. Joint Research Centre (Seville site).

[6] Bødker, S. 2003. A for Alternatives. Scandinavian Journal of Information Systems. 15, 1 (2003), 1.

[7] Bødker, S. and Kyng, M. 2018. Participatory Design That Matters-Facing the Big Issues. ACM Trans. Comput. -Hum. Interact. 25, 1 (Feb. 2018), 4:1-4:31.

[8] Bossen, C. et al. 2010. User Gains and PD Aims: Assessment from a Participatory Design Project. Proceedings of the 11th Biennial Participatory Design Conference (New York, NY, USA, 2010), 141-150.

[9] Bratteteig, T. and Wagner, I. 2016. What is a participatory design result? Proceedings of the 14th Participatory Design Conference: Full papers-Volume 1 (2016), 141-150.

[10] Carroll, J.M. et al. 2000. The Development of Cooperation: Five Years of Participatory Design in the Virtual School. Proceedings of the 3rd Conference on Designing Interactive Systems: Processes, Practices, Methods, and Techniques (New York, NY, USA, 2000), 239-251.

[11] Carroll, J.M. and Rosson, M.B. 2007. Participatory design in community informatics. Design Studies. 28, 3 (May 2007), 243-261.

[12] Clement, A. and Van den Besselaar, P. 1993. A retrospective look at $\mathrm{PD}$ projects. Communications of the ACM. 36, 6 (1993), 29-37.

[13] Computing At School: https://www.computingatschool.org.uk. Accessed: 2019-08-29.

[14] Dalsgaard, P. 2010. Challenges of participation in large-scale public projects. Proceedings of the 11th Biennial Participatory Design. (2010).

[15] Danish Ministry of Education, Curriculum for Technology Comprehension: https://www.uvm.dk//media/filer/uvm/aktuelt/pdf18/181221-laeseplanteknologiforstaaelse.pdf?la $=d a$.

[16] Del Gaudio, C. et al. 2014. The Influence of Local Powers on Participatory Design Processes in Marginalized Conflict Areas. Proceedings of the 13th Participatory Design Conference: Vol. (1) (New York, NY, USA, 2014), 131-139.

[17] Digital Technologies: https://www.australiancurriculum.edu.au/f-10curriculum/technologies/digital-technologies/. Accessed: 2019-08-29.

[18] Dindler, C. and Iversen, O.S. 2014. Relational Expertise in Participatory Design. Proceedings of the 13th Participatory Design Conference: Research Papers - Vol. 1 (New York, NY, USA, 2014), 41-50.

[19] Ehn, P. 2008. Participation in Design Things. Proceedings of the Tenth Anniversary Conference on Participatory Design 2008 (Indianapolis, IN, USA, 2008), 92-101.

[20] Frauenberger, C. et al. 2018. On scale, dialectics, and affect. Proceedings of the 15th Participatory Design Conference on Full Papers - PDC '18.

[21] Gärtner, J. and Wagner, I. 1996. Mapping Actors and Agendas: Political Frameworks of Systems Design and Participation. Hum. -Comput. Interact. 11, 3 (Sep. 1996), 187-214.

[22] home: https://www.coolthink.hk/en. Accessed: 201908-29.

[23] Huybrechts, L. et al. 2017. Institutioning: Participatory Design, Co-Design and the public realm. CoDesign. Vol. 13 (3), 148-159.

[24] Iversen, O.S. et al. 2018. From computational thinking to computational empowerment: a 21 st century PD agenda. $P D C$ (1) (2018), 7-1.

[25] Iversen, O.S. and Dindler, C. 2014. Sustaining participatory design initiatives. CoDesign. 10, 3-4 (Jul. 2014), 153-170.

[26] K-12 Computer Science Framework: https://k12cs.org. Accessed: 2019-08-29.

[27] Karasti, H. 2014. Infrastructuring in Participatory Design. Proceedings of the 13th Participatory Design Conference: Vol. (1) (New York, NY, USA, 2014), 141-150.

[28] Kyng, M. 1994. From subversion to hype: On political and technical agendas in PD. Proceedings of the 3rd Biennial Conference on Participatory Design (1994).

[29] Kyng, M. 2015. On Creating and Sustaining Alternatives: The Case of Danish Telehealth. Proceedings of The Fifth Decennial Aarhus Conference on Critical Alternatives (Aarhus, Denmark, 2015), 5-16.

[30] Merkel, C.B. et al. 2005. Sustaining computer use and learning in community computing contexts: Making technology part of who they are and what they do. The Journal of Community Informatics. 1, 2 (2005).

[31] Oostveen, A.-M. and van den Besselaar, P. 2004. From Small Scale to Large Scale User Participation: A Case Study of Participatory Design in E-Government Systems.

[32] Poderi, G. and Dittrich, Y. 2018. Participatory Design and Sustainability: A Literature Review of PDC Proceedings. Proceedings of the 15th Participatory Design Conference: Vol (2) (New York, NY, USA, 2018), 2:1-2:5.

[33] Saad-Sulonen, J. et al. 2018. Unfolding participation over time: temporal lenses in participatory design. CoDesign. 14, 1 (Jan. 2018), 4-16.

[34] Shapiro, D. 2005. Participatory Design: The Will to Succeed. Proceedings of the 4th Decennial Conference on Critical Computing: Between Sense and Sensibility 
(New York, NY, USA, 2005), 29-38.

[35] Simonsen, J. and Hertzum, M. 2008. Participative design and the challenges of large-scale systems: Extending the iterative PD approach. of the tenth anniversary conference on .... (2008).

[36] Simonsen, J. and Hertzum, M. 2012. Sustained Participatory Design: Extending the Iterative Approach. Design Issues. 28, 3 (Jul. 2012), 10-21.

[37] Simonsen, J. and Robertson, T. 2012. Routledge International Handbook of Participatory Design. Routledge.

[38] Smith, R.C. and Iversen, O.S. 2018. Participatory design for sustainable social change. Design Studies, Vol. 59, 9-36.

[39] Teli, M. 2015. Computing and the common: hints of a new utopia in participatory design. Proceedings of The Fifth Decennial Aarhus Conference on Critical Alternatives (2015), 17-20.

[40] Winschiers-Theophilus, H. et al. 2010. Being Participated: A Community Approach. Proceedings of the 11th Biennial Participatory Design Conference (New York, NY, USA, 2010), 1-10. 